\title{
Baixo crescimento econômico e melhora do mercado de trabalho - Como entender a aparente contradição?
}

JO $\tilde{A} O S A B O I A^{I}$

\section{Introdução}

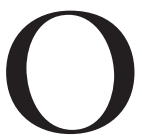
ANO 2003 foi muito especial. O Brasil tinha acabado de eleger Lula seu presidente e a elite estava preocupada com os novos rumos da economia. O país vinha de um longo período de baixo crescimento durante os dois mandatos de Fernando Henrique Cardoso (2,3\% ao ano). ${ }^{1}$

As primeiras medidas do novo governo foram bastante cautelosas com repercussões negativas sobre o crescimento econômico que não passou de 1,2\% naquele ano. A partir de 2004, entretanto, beneficiado por uma conjuntura internacional favorável e por uma política interna de distribuição de renda e fortalecimento do consumo, o país voltou a crescer, apresentando no quinquênio 2004/2008 aumento do PIB de quase 5\% anuais.

No último trimestre de 2008, entretanto, a crise internacional atingiu o país, levando o governo a tomar uma série de medidas para tentar minimizar seus efeitos. Após a breve recessão de 2009, e economia cresceu 7,5\% em 2010, taxa essa não vista no Brasil desde meados da década de 1980.

A recuperação durou pouco e, a partir de 2011, a economia entrou em uma nova fase de baixo crescimento que dura até os dias de hoje e que provavelmente permanecerá pelos próximos anos. No triênio 2011/2013 o crescimento não passou de $2,1 \%$ anuais.

Apesar das idas e vindas da economia brasileira desde 2003, o mercado de trabalho tem apresentado resultados bastante satisfatórios. A taxa de desemprego continua em trajetória descendente. O nível de renda da população permanece crescendo. A formalização do mercado de trabalho aumentou bastante nos últimos anos e se mantém em elevação. Apesar da recente desaceleração na melhora de seus indicadores, o mercado de trabalho continua produzindo números relativamente favoráveis. ${ }^{2}$

Nosso principal objetivo neste artigo é procurar entender esse aparente desencontro entre o comportamento da economia e do mercado de trabalho nos últimos anos, apontando para as principais causas que poderiam explicar a 
continuidade da melhora do mercado de trabalho, especialmente após a desaceleração da economia a partir de $2011 .{ }^{3}$ Além disso, busca-se qualificar os avanços obtidos e apresentar os desafios para os próximos anos.

\section{Forte geração de empregos de baixa remuneração}

Os números são impressionantes quando se analisa a quantidade de empregos gerados nos últimos anos. Tomando-se, por exemplo, os dados do Cadastro Geral de Empregados e Desempregados do Ministério do Trabalho e Emprego (Caged), ${ }^{4}$ que informa a criação líquida de empregos formais no país, observa-se que nos dez anos que vão de 2004 a 2013 foram gerados 13,4 milhões de empregos. ${ }^{5}$

Houve anos excepcionais, como em 2010, com a criação de mais de 2,1 milhões de empregos. Mesmo na recessão de 2009 houve quase um milhão de novos empregos formais. No triênio 2011/2013, de desaceleração da economia, o Caged levantou 3,2 milhões de novos empregos, o que não deixa de ser surpreendente. Cabe, entretanto, observar a queda nos dois últimos anos, representando os menores valores desde 2003. O Gráfico l ilustra a evolução da geração de empregos formais no período.

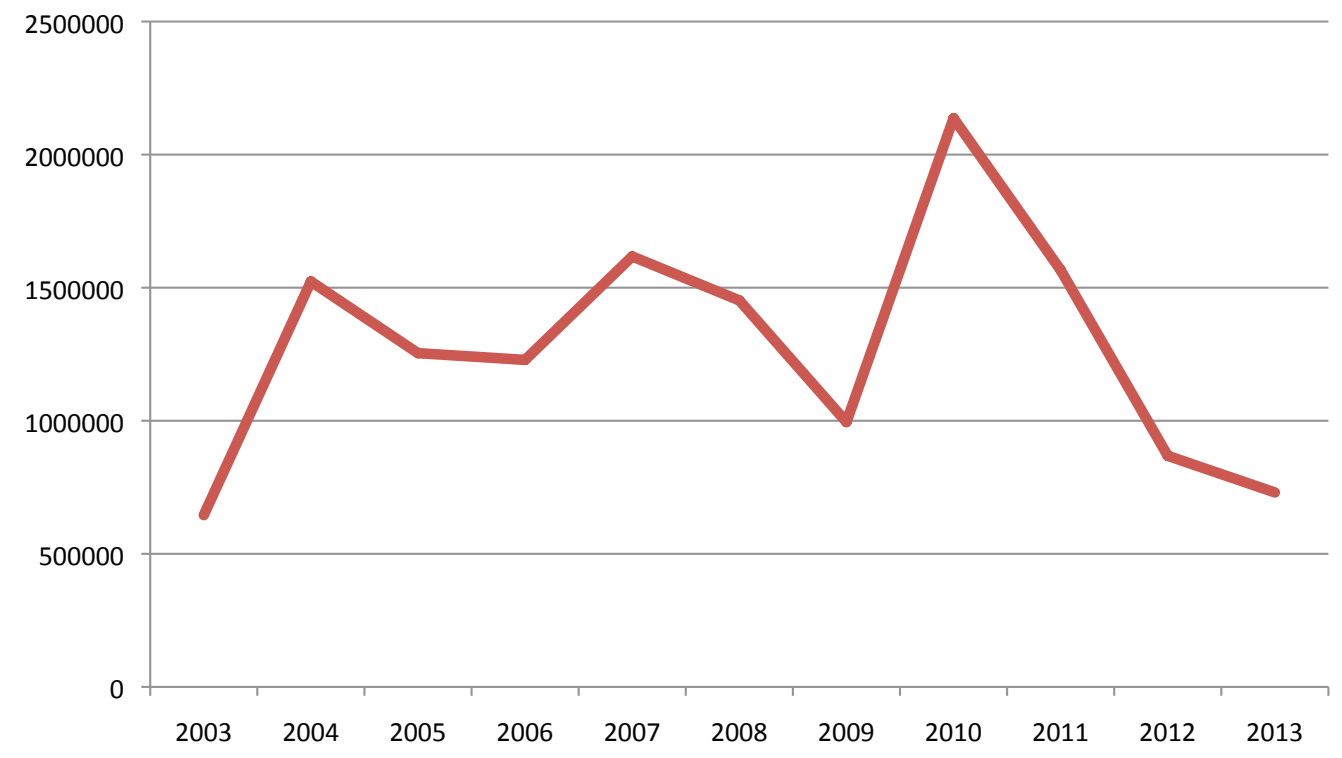

Fonte: Caged e Ipeadata.

Gráfico l - Geração de emprego formais - 2003/2013

Os dados se tornam menos impressionantes quando são analisados os resultados da Tabela 1 referentes aos salários oferecidos pelas novas vagas. A criação líquida de empregos no período 2011/2013 esteve concentrada na faixa que vai até dois Salários Mínimos (SM). A partir desse nível houve redução de empregos. Em alguns segmentos de serviços especializados, como nas áreas médica e de ensino, e em determinados setores da indústria, a geração de empregos atinge níveis salariais mais elevados, mas para o conjunto do mercado de trabalho ela está limitada aos salários mais baixos. 
Tabela 1 - Geração de empregos formais por faixa de salários mínimos - 2011/2013

\begin{tabular}{c|c|c|c|cc}
\hline Faixa de SM & 2011 & 2012 & 2013 & Total & $\%$ \\
\hline Até 1.0 & 569.399 & 408.129 & 372.391 & 1.349 .919 & 42,8 \\
\hline 1.01 a 1.5 & 1.224 .785 & 888.793 & 917.044 & 3.030 .622 & 96,0 \\
\hline 1.51 a 2.0 & 117.812 & 38.415 & -51.772 & 104.455 & 3,3 \\
\hline 2.01 a 3.0 & -139.636 & -210.210 & -196.928 & -546.774 & $-17,3$ \\
\hline 3.01 a 4.0 & -97.684 & -105.818 & -119.477 & -322.979 & $-10,2$ \\
\hline 4.01 a 5.0 & -37.273 & -34.355 & -59.707 & -131.335 & $-4,2$ \\
\hline 5.01 a 7.0 & -38.599 & -52.948 & -52.034 & -143.581 & $-4,5$ \\
\hline 7.01 a 10.0 & -17.266 & -22.698 & -33.245 & -73.209 & $-2,3$ \\
\hline 10.01 a 15.0 & -8.214 & -18.918 & -22.743 & -49.875 & $-1,6$ \\
\hline 15.01 a 20.0 & -7.282 & -8.449 & -11.716 & -27.447 & $-0,9$ \\
\hline Mais de 20.0 & -7.517 & -11.380 & -15.269 & -34.166 & $-1,1$ \\
\hline Total & 1.558 .525 & 870.561 & 726.544 & 3.155 .630 & 100 \\
\hline
\end{tabular}

Fonte: Caged e Ipeadata.

\section{A queda contínua da taxa de desemprego}

A evolução da taxa de desemprego segundo a Pesquisa Mensal de Emprego (PME) do $\mathrm{IBGE}^{6}$ confirma os dados favoráveis da forte geração de emprego. Partindo do "fundo do poço" do mercado de trabalho em 2003, quando superava $12 \%$, ela foi sendo reduzida ano após ano, até atingir valores pouco superiores a $5 \%$ em 2012 e 2013, conforme mostrado no Gráfico 2.

Apenas em 2009, por conta das dificuldades da economia após o início da crise internacional, houve ligeira elevação. Nota-se também que em 2013 a queda foi pequena em função da desaceleração da economia ao final do período.

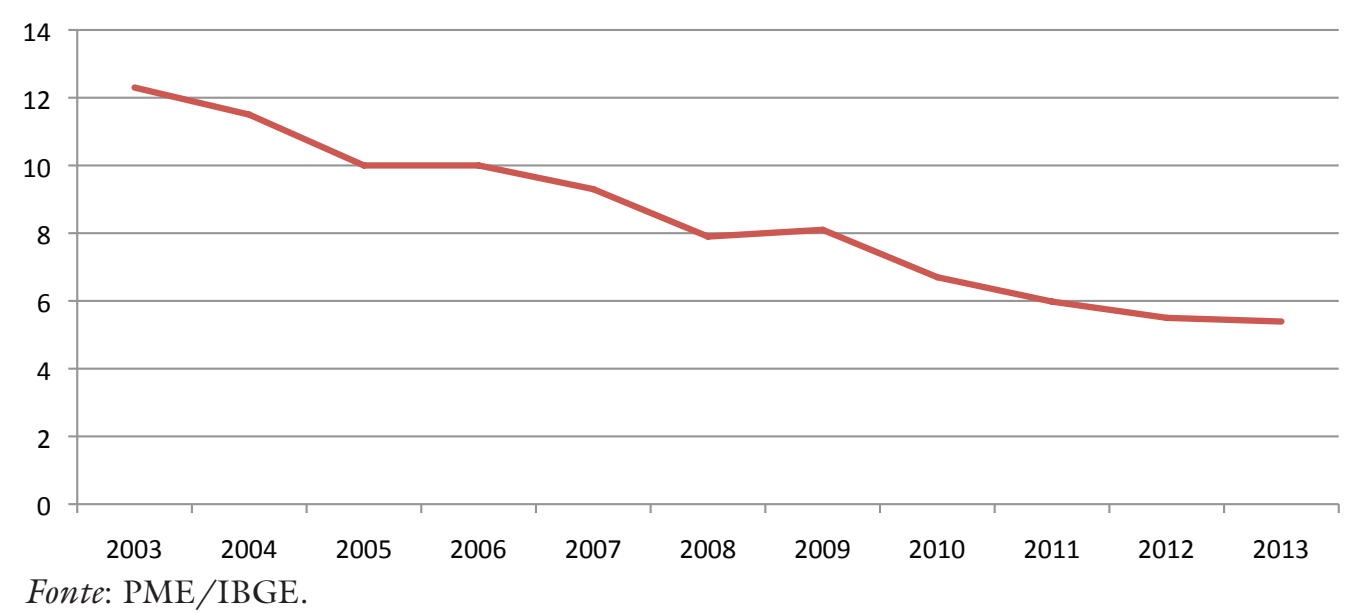

Gráfico 2 - Taxa de Desemprego - 2003/2013 
Uma taxa de desemprego da ordem de $5 \%$ como a obtida atualmente pela PME é baixa em qualquer parte do mundo, mas ela precisa ser qualificada no caso brasileiro.

Em primeiro lugar, ela é levantada em apenas seis regiões metropolitanas, deixando de fora a maior parte do mercado de trabalho do país. Informações levantadas em outras fontes como a PNAD e a nova PNAD Contínua apresentam taxas de desemprego um pouco mais elevadas. ${ }^{7}$

Em segundo lugar, num país com um grande setor informal como no caso brasileiro, a baixa taxa de desemprego ocorre simultaneamente com alta precariedade e informalidade no mercado de trabalho, representada por um grande número de pessoas ocupadas recebendo baixos salários, sem carteira assinada, sem contribuição previdenciária ou trabalhando por conta própria. São situações típicas de trabalho de baixa produtividade. O próprio fato de a geração líquida de empregos no setor formal estar concentrada nos menores salários aponta para o baixo nível de produtividade de tais empregos.

\section{O salário mínimo}

\section{e o crescimento da remuneração média do trabalho}

Um dos fatos mais notáveis verificados nos últimos anos para aqueles que se interessam pelo estudo do mercado de trabalho e da distribuição de renda no Brasil foi o forte crescimento do Salário Mínimo (SM).

O SM já vinha crescendo desde a segunda metade dos anos 1990 por conta do final da hiperinflação obtida com o Plano Real. Seu forte crescimento, entretanto, passa a ocorrer somente a partir de 2004, quando a conjuntura política e econômica do país favoreceu a obtenção de reajustes mais generosos.

As discussões no Congresso por ocasião dos reajustes anuais acabaram desembocando numa regra aplicada a partir de 2009, em que, além da correção pela inflação (INPC), passa a ser concedido o aumento do PIB de dois anos anteriores. ${ }^{8}$ Tal regra terminará em 2015 quando deverá ser renovada ou definida outra fórmula para os futuros reajustes para o SM. ${ }^{9}$

O resultado da política do SM sobre a evolução de seu valor pode ser observado no Gráfico 3. No período entre 2003 e 2013, o SM cresceu 74\% em termos reais.

Tendo em vista a importância do SM na determinação dos demais salários, tanto no setor formal quanto no informal, não causa surpresa verificar que o nível médio de remuneração no mercado de trabalho também cresceu bastante no período. Segundo os dados da PME, houve aumento de 30\% do salário médio em termos reais entre 2003 e 2013. O Gráfico 3 mostra duas curvas quase paralelas representando a evolução do SM e da remuneração média do trabalho no período. ${ }^{10}$ 


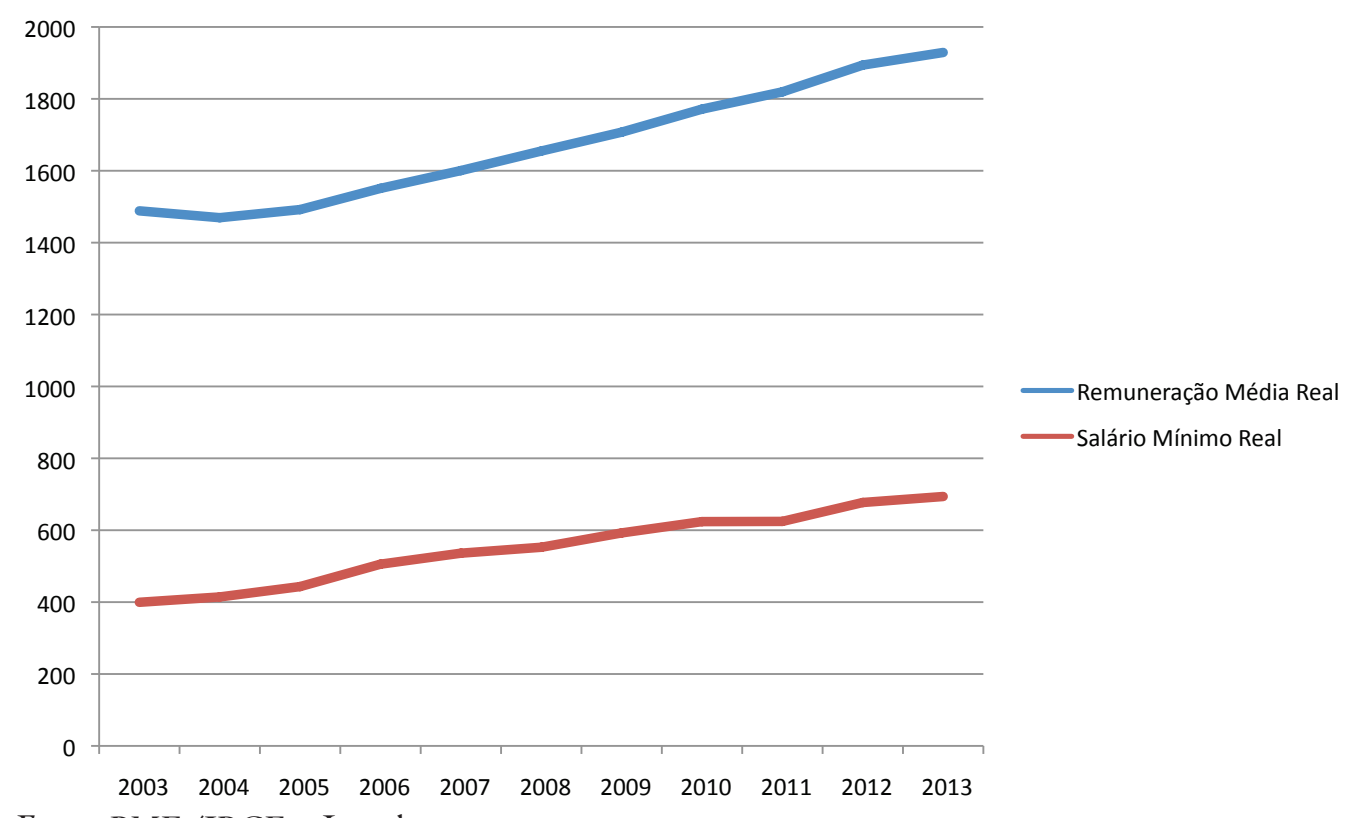

Fonte: PME/IBGE e Ipeadata.

Gráfico 3 - Salário mínimo e remuneração média real - 2003/2013

( R\$ de dezembro de 2013)

\section{Trabalhadores com mais anos de estudo de qualidade questionável}

O nível de escolaridade da população em geral aumentou muito nos últimos anos. Embora o analfabetismo permaneça elevado entre a população mais velha, praticamente todas as crianças na faixa etária do Ensino Fundamental estão matriculadas nas escolas. Contribuiu para isso não apenas a própria política educacional do governo, como também o Programa Bolsa Família (PBF), que inclui entre as obrigações da população beneficiária a matrícula de seus filhos no sistema escolar.

O nível de escolaridade da força de trabalho no Brasil é reconhecidamente muito baixo na comparação internacional, com repercussões negativas sobre o nível de produtividade do trabalho. Mas da mesma forma que no caso da população em geral, também tem havido aumento da escolaridade da população ocupada.

Os melhores empregos exigem um nível de escolaridade mínimo equivalente ao ensino secundário (onze anos de estudo) ou, preferencialmente, universitário, no qual os salários são bem mais elevados. Isso tem induzido os jovens trabalhadores a adiarem a entrada no mercado de trabalho e permanecerem por mais tempo na escola. Com isso, nos últimos anos, tem sido observado um excepcional crescimento na escolaridade da mão de obra medida em anos de estudo como confirmado pelo Gráfico 4.

Infelizmente, como será visto mais adiante, o crescimento do número de anos de estudo dos trabalhadores não tem resultado em aumento proporcional 
da produtividade, levantando a questão da baixa qualidade do ensino no país que precisaria passar por uma grande melhora. Não se trata, portanto, de apenas estudar mais anos, mas principalmente de aumentar a qualidade do ensino público que resulte em crescimento da produtividade do trabalho. ${ }^{11}$

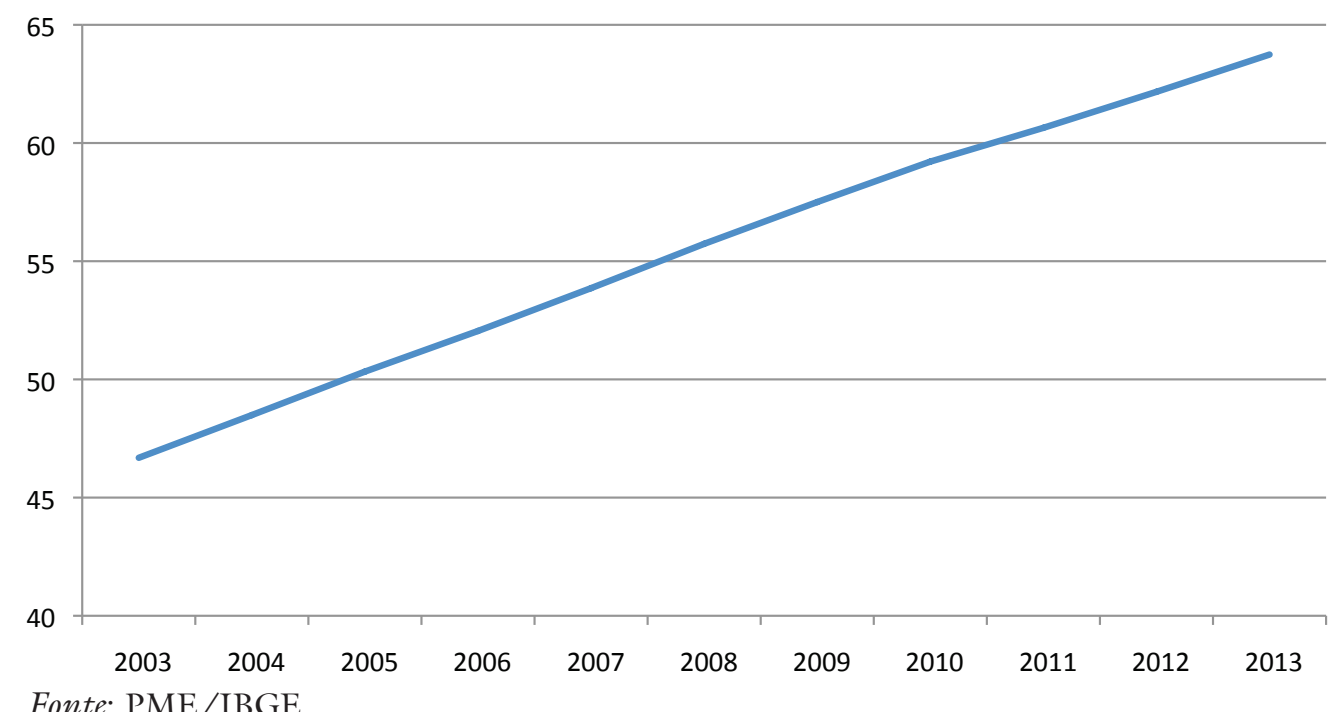

Fonte: PME/IBGE.

Gráfico 4 - Trabalhadores com onze anos de estudo ou mais - 2003/2013 (\%)

\section{Maior formalização de relações \\ de trabalho ainda muito informais}

Outra área em que houve grandes avanços no mercado de trabalho brasileiro foi na formalização das relações de trabalho. Segundo a PME, o percentual de empregados com carteira assinada passou de $44 \%$ para $55 \%$ da População Economicamente Ativa (PEA). ${ }^{12} \mathrm{O}$ Gráfico 5 ilustra a evolução no período.

Tal resultado é a combinação de diversos fatores. ${ }^{13}$ Por um lado, a própria sociedade passou a dar mais importância a seus direitos conforme atestam as manifestações populares ocorridas no país desde meados de 2013. No caso dos direitos trabalhistas, seu não cumprimento costuma resultar em processos na Justiça do Trabalho, usualmente ganhos pelos empregados. Por outro lado, o governo aumentou a fiscalização nas empresas para cobrar o cumprimento da legislação trabalhista. ${ }^{14}$ Finalmente, a própria melhoria do mercado de trabalho observada no período aumentou o poder de barganha dos trabalhadores, com a possibilidade de escolherem melhores empregos que respeitam a legislação trabalhista.

Apesar dos avanços, a situação permanece bastante precária. Se nas seis regiões metropolitanas cobertas pela PME apenas 55\% das pessoas ocupadas possuem a carteira de trabalho assinada, pode-se imaginar o que ocorre nas regiões menos desenvolvidas e no interior do país, onde a informalidade é bem mais elevada. ${ }^{15}$ 


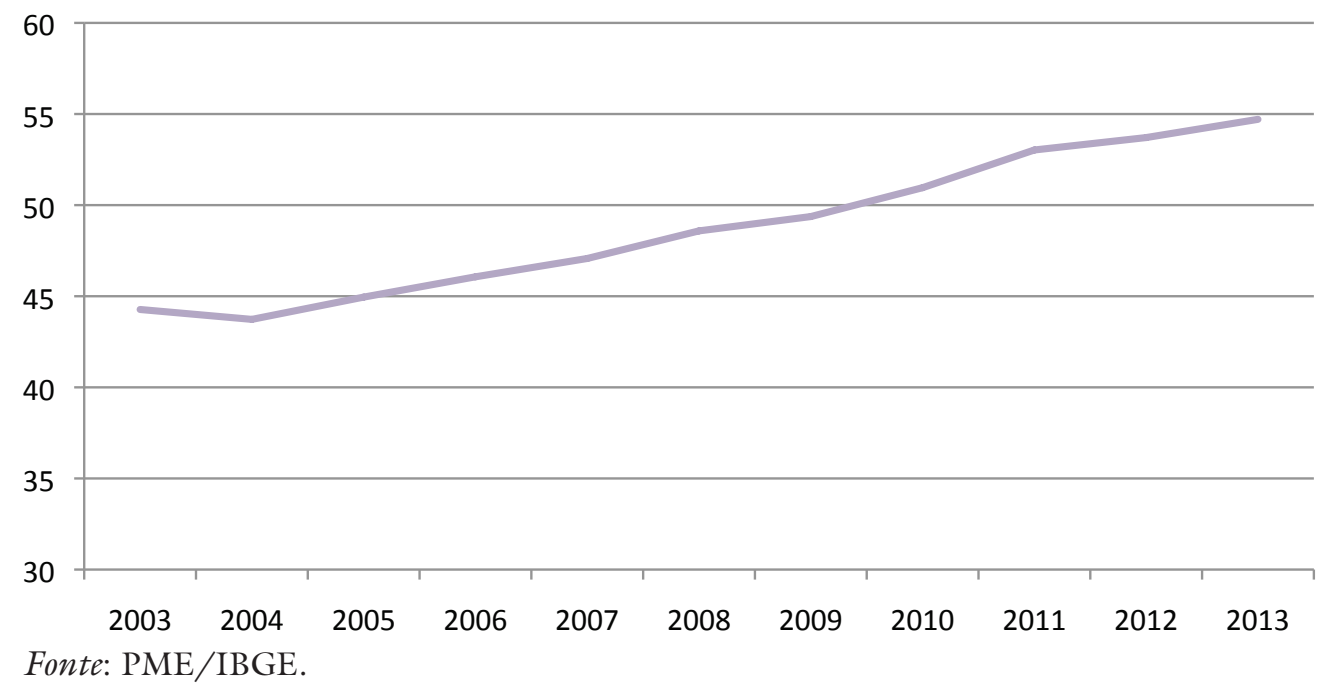

Gráfico 5 - Emprego formal (com carteira assinada) - 2003/2013 (\%)

\section{A transição demográfica e as mudanças na PEA}

A transição demográfica ${ }^{16}$ que vem ocorrendo no Brasil tende a reduzir a pressão de oferta de mão de obra no mercado de trabalho, contribuindo para a redução da taxa de desemprego. Atualmente, a taxa de fecundidade do país é da ordem de 1,9, significando que está abaixo da taxa de reposição correspondente a dois filhos por mulher. Com isso a população continuará crescendo a taxas decrescente nos próximos anos devendo se estabilizar (e até mesmo cair) em um futuro não muito distante.

Recentemente, tem sido observado um envelhecimento da população voltada para o mercado de trabalho. O número de pessoas na PEA segundo a faixa etária tem mostrado uma clara tendência de redução entre os mais jovens até 24 anos, em contrapartida ao aumento daqueles com 50 anos ou mais.

Tal resultado é a combinação do próprio efeito demográfico de envelhecimento populacional ao lado da tendência de as pessoas mais jovens permanecerem mais tempo na escola para entrarem no mercado de trabalho com ao menos o ensino médio completo.

Tal movimento é favorável à redução da taxa de desemprego, mas ao mesmo tempo levanta uma nova questão no futuro quando poderá haver falta de mão de obra (qualificada ou não) caso não haja aumento da produtividade do trabalho. Passaremos a discutir essa questão a seguir.

\section{Até quando dá para continuar gerando empregos com pouco crescimento econômico?}

Da mesma forma que no último triênio, em princípio, o país pode continuar gerando empregos nos próximos anos em que as perspectivas de crescimento econômico são desfavoráveis. A questão que se coloca é até que ponto tais empregos serão bons empregos com alto nível de qualificação ou, ao contrário, empregos de baixos salários e produtividade. 
De acordo com os dados do Caged, no triênio 2011/2013, três de cada quatro empregos gerados no setor formal da economia brasileira estão localizados no setor terciário, sendo dois em serviços e um no comércio. $O$ padrão típico do terciário tem sido a criação de empregos de baixos salários e produtividade. Portanto, não há nenhum desafio para o país continuar criando empregos poucos produtivos em um novo período de baixo crescimento econômico.

Com a transição demográfica e o envelhecimento da PEA, entretanto, os riscos de falta de mão de obra nos próximos anos aumentam. Portanto, mesmo a geração de empregos com baixos salários e qualificação estaria ameaçada pela redução e envelhecimento da PEA em médio prazo.

Os dados relativos ao nível de produtividade da economia brasileira são preocupantes. Comparações com outros países mostram que a produtividade do trabalho no Brasil era de apenas $18 \%$ da norte-americana em 2012, resultado inferior ao apresentado por outras economias latino-americanas como Argentina, Chile, Colômbia e México. No período 2000/2012 o crescimento da produtividade do trabalho não passou de $1 \%$ ao ano. ${ }^{17}$

No caso do setor de serviços, houve queda da produtividade do trabalho na década de 2000, representando, em 2008, apenas 26\% do nível de produtividade do trabalho encontrado nos Estados Unidos e abaixo do observado em Chile, México, Uruguai e Argentina. Portanto, há muito a ser feito no país para a elevação da produtividade do trabalho sob o risco de comprometimento do crescimento econômico no futuro. ${ }^{18}$

Assim, o desafio que se coloca ao país não é a geração de empregos, mas sim a geração de bons empregos.

A saída para esse desafio passa por algumas questões.

O ponto de partida deve ser a retomada dos investimentos que atualmente não dão conta das necessidades do país para a retomada do crescimento. Comparações internacionais colocam a atual taxa de investimentos brasileira, da ordem de $17 \%$ a $18 \%$ do PIB, abaixo da encontrada na maior parte dos países com nível de desenvolvimento semelhante. Tais investimentos, tanto públicos quanto privados, são fundamentais para o crescimento da produtividade da economia.

Combinados com o aumento da escolaridade da população e uma maior preocupação com a qualidade do ensino público em seus diversos níveis, terá como consequência inevitável o aumento da produtividade do trabalho, necessária para a geração de empregos de alta qualidade, e para evitar que haja falta de mão de obra por ocasião da retomada do crescimento econômico no futuro. Iniciativas governamentais como o Pronatec são bem-vindas, mas precisam ser complementadas com outras medidas para se criar um ambiente favorável à retomada dos investimentos no país. 


\section{Observações finais}

Uma das questões que têm levantado dúvidas e busca de explicações nos últimos anos é a simultaneidade do comportamento favorável do mercado de trabalho, ao mesmo tempo que a economia brasileira tem crescido pouco e encontra-se em franco processo de desaceleração.

Neste artigo foram discutidos vários aspectos da performance recente do mercado de trabalho, tais como a queda do desemprego, o aumento do salário mínimo e dos salários em geral, o crescimento da formalização do trabalho, o aumento da escolaridade dos trabalhadores, e os efeitos da transição demográfica do país.

Foi argumentado que a forte geração de empregos observada no período está associada à criação de empregos majoritariamente localizados no setor terciário com baixa produtividade e mal remunerados, sendo, portanto, um resultado compatível com o baixo crescimento econômico,

Foi destacada também a questão da transição demográfica, cujas consequências já estão aparecendo no mercado de trabalho, onde tem sido observado um menor crescimento e envelhecimento da PEA, e que poderá resultar no futuro em falta de mão de obra, seja ela qualificada ou não.

O principal argumento levantado no texto para que o país possa voltar a crescer e criar bons empregos está centrado no baixo nível de produtividade do trabalho que precisa ser aumentado. Para tanto será necessário melhorar a qualidade do ensino público em geral, que não tem acompanhado o movimento da população em busca de aumento de sua escolaridade.

Simultaneamente, será preciso criar condições favoráveis à retomada dos investimentos públicos e privados que possa se refletir no aumento da produtividade da economia como um todo.

\section{Notas}

$1 \mathrm{O}$ crescimento da economia é medido pela variação do Produto Interno Bruto (PIB).

2 Este artigo foi preparado em meados de 2014 quando os resultados do mercado de trabalho continuavam relativamente favoráveis. Saboia e Kubrusly (2013) apresentam um indicador multidimensional que confirma a melhora do mercado de trabalho no período analisado.

3 Para uma discussão recente sobre a permanência do baixo desemprego apesar da má performance da economia, ver Barboza (2014).

4 Os dados do Caged são informados pelas empresas com as admissões e os desligamentos ocorridos a cada mês, permitindo uma estimativa para a geração de empregos formais no país, excluindo a administração pública.

5 Apenas para efeito de comparação, nos quatro anos anteriores (2000/2003) os novos empregos gerados não passaram de 2,7 milhões. 
6 A PME é a principal referência para o cálculo da taxa de desemprego no país, embora cubra apenas seis regiões metropolitanas - São Paulo; Rio de Janeiro; Belo Horizonte; Porto Alegre; Salvador; e Recife.

7 A Pesquisa Nacional por Amostra de Domicílios (PNAD) do IBGE é uma pesquisa realizada uma vez por ano com cobertura nacional. A PNAD Contínua é uma nova pesquisa do IBGE que substituirá a PNAD e a PME cobrindo todo o país e apresentando dados trimestrais. Segundo a PNAD, a taxa de desemprego em 2012 era de 6,1\%. Segundo a PNAD Contínua, atingia 7,4\% no segundo trimestre de 2013.

8 A razão para a utilização do crescimento do PIB de dois anos anteriores e não do último ano é técnica na medida em que o SM é reajustado em janeiro, enquanto a primeira estimativa de crescimento da economia de um determinado ano só é divulgada no final de fevereiro do ano seguinte.

9 Sobre essa questão, ver Filgueiras (2014).

$10 \mathrm{O}$ fato de a geração líquida de empregos estar concentrada na faixa até dois SM não impede que a remuneração média tenha crescido no período e atingido em 2013 quase três SM. Isso pode ser explicado, em parte, pelo próprio crescimento do salário mínimo. Além disso, o volume de empregos gerados é relativamente pequeno quando comparado com o volume total de empregos, minimizando seu efeito sobre a remuneração média.

11 Criado em 2011, com o objetivo de ampliar a oferta de cursos de educação profissional e tecnológica, o Programa Nacional de Acesso ao Ensino Técnico e Emprego (Pronatec) poderá vir a dar uma contribuição nesse sentido.

12 A PEA é a soma das pessoas ocupadas com as pessoas desocupadas (desempregadas).

13 Cardoso Jr. (2007) apresenta uma série de razões para o aumento da formalização do trabalho no Brasil.

14 Para uma discussão sobre a fiscalização e seus resultados sobre a formalização das relações de trabalho, ver Simão (2009).

15 A melhor fonte de dados para o estudo da informalidade no restante do país é a PNAD, que cobre as diversas regiões.

16 Sobre a questão da transição demográfica no Brasil ver, por exemplo, Alves (2013).

17 Para um aprofundamento da discussão sobre a produtividade do trabalho no Brasil e comparativamente a outros países, ver Bonelli e Fontes (2013).

18 De Negri e Cavalcante (2013) também chamam a atenção que o crescimento da economia se beneficiou nos últimos anos da entrada de novos trabalhadores, mas que essa alternativa encontra-se atualmente limitada. Assim, seria necessário o aumento da produtividade do trabalho para a retomada do crescimento.

\section{Referências}

ALVES, J. E. D. O bônus demográfico no Brasil. Jornal dos Economistas, Corecon-RJ e Sindecon-RJ, Rio de Janeiro, n.292, nov. 2013.

BARBOZA, R. de M. PIB e desemprego no Brasil. Valor Econômico, São Paulo, 16.1.2014.

BONELLI, R.; FONTES, J. O desafio brasileiro no longo prazo. In: BONELLI, R.; 
PINHEIRO, A. C. (Org.) Ensaios IBRE de Economia Brasileira - I. Rio de Janeiro: IBRE-FGV, 2013.

CARDOSO JUNIOR, J. C. De volta para o futuro? As fontes de recuperação do emprego formal no Brasil e as condições para sua sustentabilidade temporal. Texto para Discussão 1310. IPEA, Brasília, nov. 2007.

DE NEGRI F.; CAVALCANTE, L. R. Evolução recente dos indicadores de produtividade no Brasil. Radar, Tecnologia, Produção e Comércio Exterior, IPEA, n.28, ago. 2013.

FILGUEIRAS, S. O dilema do salário mínimo. Brasil Econômico, Brasília, 12.5.2014.

SABOIA, J.; KUBRUSLY, L. S. Indicadores para o mercado de trabalho metropolitano no Brasil. Rio de Janeiro: Instituto de Economia - UFRJ, 2013.

SIMÃO, A. Sistema de vigilância e fiscalização do trabalho no Brasil: efeitos sobre a expansão do emprego formal no período 1999-2007. Boletim Mercado de Trabalho Conjuntura e Análise, Rio de Janeiro, IPEA, n.39, maio 2009.

RESUMO - O artigo discute a evolução favorável do mercado de trabalho a partir de 2004, quando passou a apresentar, simultaneamente, aumento dos salários, redução do desemprego e da informalidade. Ênfase especial é dada ao período 2011/2013 quando a economia desacelerou fortemente e o mercado de trabalho continuou apresentando resultados positivos. $\mathrm{O}$ argumento central é que tal performance ocorreu por conta do baixo nível da produtividade do trabalho, que favoreceu a criação de uma grande quantidade de empregos pouco produtivos e mal remunerados.

PALAVRAS-CHAVE: Mercado de trabalho, Emprego, Desemprego, Salário, Informalidade. ABSTRACT - This paper discusses the favorable evolution of the Brazilian job market since 2004, when wages began to increase and both unemployment and informal employment decreased. It focus particularly on the $2011 / 2013$ period, when the economy slowed down sharply, but the labor market continued to show positive results. The central argument is that this type of performance derives from a low level of labor productivity that is conducive to the creation of a large number of low-productivity, poorly paid jobs.

KEYWORDS: Job market, Jobs, Unemployment, Wages, Informal economy.

João Saboia é professor titular do Instituto de Economia da Universidade Federal do Rio de Janeiro. O autor agradece o apoio de Giovanna Loiola e Pilar Picon na preparação do material empírico do artigo. @-saboia@ie.ufrj.br

Recebido em 24.6.2014 e aceito em 2.7.2014.

I Universidade Federal do Rio de Janeiro. Rio de Janeiro/RJ, Brasil. 